see that no one makes personal profit out of this situation to the detriment of the world-wide distribution of the new products.

\section{Edison's Birthday}

To commemorate the 110th anniversary of the birth of Thomas Alva Edison, which took place on February 11, 1847, Science Service of America has produced a booklet for all its Science Clubs indicating experiments connected with Edison's work which could be carried out by young people. The booklet shows how exhibits of important Edison inventions could be cheaply made and how they could be used at local exhibitions arranged in connexion with the National Edison Birthday Celebration of February 11. Industries had been asked to open their factories and research laboratories to visiting students on that day. The National Edison Birthday Celebration has been conceived as an annual event in order to encourage young people to take advantage of growing opportunities for careers in science and engineering, to direct national attention to the critical shortage of scientifically trained people and to stimulate greater interest in science.

\section{Nuclear Instruments}

Nuclear Instruments is a new international journal, published by the North-Holland Publishing Co., Amsterdam, and edited by Prof. K. Siegbahn, of the University of Upsala. It is, therefore, a companion journal to Nuclear Physics, now entering its third volume. Again, the editorial board is representative of many countries, and contributions are accepted in English, French or German, with abstracts in English. Developments in accelerators, particle detection, isotope separators, mass spectrometers and related fields require at least as much research effort as the nuclear experiments which they make possible, and need to be reported in specialist papers. The purpose of Nuclear Instruments is to attract such papers, together with survey articles and book reviews. The first issue of fifty-six pages (January 1957) contains reports of the C.E.R.N. Symposium of June 1956, authoritative papers on regenerative beam extraction from accelerators, a proportional counter system with small wall effect, aberrations in a $180^{\circ}$ double focusing magnetic spectrometer, short notes on evaporation crucibles for beta-spectrometer samples and diverging electrostatic lenses in accelerators, and two book reviews. The journal has an opportunity to fill an important need. It is well laid out, and the standards of printing and reproduction of diagrams are excellent. The subscription price is $£ 610$ s., or 17 dollars, for each volume of 360 pages, and publication is bi-monthly.

\section{Bird Ringing}

IN a journal entirely devoted to the ringing of birds, the editor, Dr. W. Rydzewski, directs attention to the increasing number of inadequately addressed rings which are being reported by finders in many countries (The Ring, No. 9; November 1956), despite the fact that officially recognized rings are easily obtainable for applicants with adequate ornithological knowledge. These 'unofficial' rings often mean that 'bird-recoveries' are lost both to the ringer and the finder. To help to minimize this loss, Rydzewski suggests the compilation of an index of as many non-ornithological rings as possible and that this should then be made widely known. $\mathrm{He}$ has already begun to build up a collection of this sort. All who are interested should get in touch with Dr. Rydzewski at 1 Altyre Road, Croydon, Surrey. The Ring, which is published from that address, appears quarterly in February, May, August and November, and costs 16s., post paid.

\section{United States Radio Astronomy Observatory}

THE National Science Foundation has entered into a contract with Associated Universities, Inc., for the conduct of basic research in the field of radio astronomy. The agreement provides for the establishment of a radio astronomy observatory at Green Bank, Pocahontas County, West Virginia. Associated Universities, Inc., will construct and provide for the "management, operation and maintenance of the observatory with the primary purpose of making its facilities available for visiting scientists". The National Science Foundation will provide 4 million dollars during 1957 for the necessary facilities and equipment, including a radio telescope with a diameter of approximately $140 \mathrm{ft}$. Associated Universities, Inc., an educational corporation, initially organized under the State Board of Regents of New York, operates Brookhaven National Laboratory at Upton, New York, under contract to the Atomic Energy Commission. The corporation is sponsored by nine universities: Columbia, Cornell, Harvard, Johns Hopkins, Massachusetts Institute of Technology, Princeton, University of Pennsylvania, University of Rochester, and Yale.

\section{Fusarium Isolates from Soils}

W. L. Gondon, of the Plant Pathology Laboratory, Winnipeg, Manitoba (Canad. J. Bot., 34, 833 ; 1956), has given an account of a taxonomic study of 1,348 isolates of Fusarium found in 206 soil samples collected in 1946 ; 143 (approximately 70 per cent of the samples) were obtained from 127 localities in Manitoba; the remaining 63 (30 per cent) came from seven other provinces. Of 25,973 colonies of fungi that developed on the 2,060 soil-dilution plates involved in this study, Fusarium accounted for approximately 5 per cent. A total of fourteen species and varieties of Fusarium, classified in nine sections of the genus, were isolated. $F$. oxysporum, $F$. oxysporum var. redolens, $F$. equiseti and $F$. solani accounted for approximately 90 per cent of the total Fusarium isolates. F. oxysporum was by far the most prevalent species isolated.

\section{Ophthalmic Trial Case Lenses}

THE unanimous report of the Committee on Trial Case Lenses appointed by the Minister of Health in December 1954 to review standards for the lenses used in carrying out sight tests and the method of measuring lens powers has now been published ("Trial Case Lenses". Pp. 25. London: H.M. Stationery Office, 1956. 1s. $9 d$. net). The chairman of the Committee was Sir Stewart Duke-Elder. The ophthalmic trial case first appeared in approximately its present form about ninety years ago, when the introduction of routine testing for astigmatism brought complexity into what had hitherto been a comparatively simple process. The report, which is somewhat technical, is in two parts. In Part 1 the Committee sets out the reasons which lead it to recommend that the back vertex system of expressing and measuring lens powers becomes the accepted standard. It states that there is evidence that the manufacturing industry would welcome back vertex standardization and that most firms are now equipped 